\title{
O TRANSCONSTITUCIONALISMO COMO MÉTODO PROPULSOR DA CONCREÇÃO DOS DIREITOS COLETIVOS NA SOCIEDADE MULTICÊNTRICA
}

\author{
Juvêncio Borges Silva ${ }^{1}$ \\ Elis Betete Serrano ${ }^{2}$
}

\section{RESUMO:}

O presente trabalho objetiva explorar o método proposto pelo Professor Marcelo Neves, o transconstitucionalismo, focando na sua relação com os direitos coletivos na sociedade multicêntrica. $\mathrm{O}$ método tem crescente importância devido à falta de maneiras para resolução de atribulações entre ordens jurídicas conflitantes, buscando assim arquitetar o modo de relação entre essas ao invocar um diálogo e um consequente entrelaçamento de sapiências ao desenvolver meios de aprendizado recíproco. O autor evidencia a importância da consideração de direitos fundamentais, em especial os de natureza coletiva. Demonstra-se aqui alguns efeitos práticos da utilização da transconstitucionalismo para impulsionar direitos coletivos.

Palavras-chave: Transconstitucionalismo; Direitos Coletivos; Sociedade multicêntrica; Direitos fundamentais; Diálogo.

\section{THE TRANSCONSTITUCIONALISM AS A COLLECTIVE RIGHT'S CONCRETION SPREAD METHOD ON A MULTICENTRIC SOCIETY}

\begin{abstract}
:
This paper seeks to analyse the transconstituicionalism method proposed by Professor Marcelo Neves and its relations with the collective rights within a multicentric society. This method has been growing in importance due to lack of means for resolving conflicting legal systems. In addition, it searches to develop the relationship between those two based on dialog and, consequently, strengthening of mutual wisdom as a result of a reciprocal learning process. The author demonstrates the importance of considering fundamental rights, especially those of collective nature. It demonstrates some practical effects of using transconstituicionalism as a way of boosting collective rights development.
\end{abstract}

Keywords: Transconstituicionalism; Collective rights; Multicentric society; Fundamental rights; Dialogue.

\section{Introdução}

\footnotetext{
${ }^{1}$ Pós-doutor em direito pela Faculdade de Direito da Universidade de Coimbra. Doutor pela UNESP. Mestre pela Unicamp. Docente do Programa de Mestrado em Direitos Coletivos e Cidadania da UNAERP.

${ }^{2}$ Pós-graduanda em Direito Público. Mestrado em Direitos Coletivos e Cidadania na Universidade de Ribeirão Preto. Advogada.
} 
Diante dos avanços globais na perspectiva jurídica, principalmente quanto à evolução e consolidação dos direitos coletivos, urge a adoção de novos métodos que possibilitem a solução de casos concretos que envolvam mais de um ator internacional. Essa necessidade tem invocado uma dinâmica que inclua as ordens jurídicas em um diálogo e, através deste, o alcance de um aprendizado difuso entre elas.

É com essa preocupação que Marcelo Neves (2009) estuda a possibilidade da adoção de um método, por ele chamado de transconstitucionalismo, o qual visa delinear as formas de relação entre ordens jurídicas, de modo a poder proporcionar essa almejada aprendizagem entre elas de forma simbiótica. Dessa forma, para a realização do presente trabalho, orientouse pelo método analítico-dedutivo.

Busca-se, no caso de colisões entre concepções jurídicas diversas, respostas firmadas no entrelaçamento entre essas ordens, as quais poderão ser de proveniência estatal, local, internacional, supranacional e transnacional ou, ainda, perante mais de uma dessas ordens, dando especial ênfase às ocorridas na sociedade multicêntrica tendo em vista a grande importância destes conflitos. Importante ressaltar, desde já, que a proposta se restringe a uma conversação, de modo a não acarretar uma única unidade constitucional em todo o sistema jurídico global, tampouco o entrave ou aniquilamento das ordens jurídicas concorrentes ou cooperadoras.

Nesse ínterim, destaca-se a importância da discussão sobre direitos fundamentais, em especial, os de natureza coletiva. Os direitos coletivos, assim como os difusos e individuais homogêneos são oriundos da Constituição Federal de 1988, tendo sido materializados num primeiro momento na Política Nacional do Meio Ambiente (Lei 6.938/81), na Lei da Ação Civil Pública (Lei 7.347/85) e no Código de Defesa do Consumidor (Lei 8.078/90).

A compreensão de tais matérias, inclusive fazendo uma relação com cidadania, é de suma importância uma vez que os direitos coletivos, historicamente, podem ser visualizados como resultado de conquistas sociais, sendo tido como instrumentos processuais eficientes no atendimento da conjuntura de pessoas atingida, de maneira a possibilitar a solução dos conflitos coletivos de ordem econômica, social ou cultural.

Os direitos coletivos, por sua vez, serão definidos principalmente conforme o artigo 81, Parágrafo Único, inciso II, do Código de Defesa do Consumidor (Lei 8.078/90), sendo caracterizados como aqueles direitos em que há determinação de seus titulares em um grupo, 
categoria ou classe, ligados por uma relação jurídica base em que o bem jurídico tutelado seja indivisível.

O presente trabalho dimensionará o estudo de Marcelo Neves e suas possibilidades práticas, analisando casos verídicos sobre os quais o método do transconstitucionalismo tenha ou não imperado, bem como suas possibilidades futuras.

Acredita-se que talvez não se alcance a cura para toda a problemática existente em torno dessa natureza de conflitos. Todavia, é possível, através do estudo proposto pelo método do transconstitucionalismo, enxergar uma preciosa trilha para a conquista de remédios para casos tão emblemáticos e substanciais, como são os choques entre ordens jurídicas que envolvam direitos coletivos.

Como atualmente, na perspectiva de desavenças transterritoriais, o problema consiste muitas vezes nas controvérsias atinentes a direitos coletivos, intenta-se investigar a expectação de utilização do método do transconstitucionalismo como meio de realce dos direitos coletivos. Neste sentido, será possível notar, como melhor alternativa, a conversação entre as ordens jurídicas, em uma sociedade multicêntrica, sob o fundamento metódico conciliatório proposto pelo transconstitucionalismo, ao invés da imposição pela autoridade.

\section{Análise dos direitos coletivos e sua crescente importância}

Sob uma concepção ampla, direitos coletivos expressa os interesses de grupos, classes de pessoas ou transindividuais. A expressão "interesses coletivos", por sua vez, foi utilizada pela Constituição Federal de 1988, em seu artigo 129, inciso III, quando trata da ação civil pública como uma das funções institucionais do Ministério Público. Aparece também no Código de Defesa do Consumidor (CDC), quanto à disciplina da ação coletiva.

Entretanto, o CDC não se restringiu somente a esse amplo conceito, mas inovou em tratar, no Parágrafo Único do art. 81, das espécies de interesses coletivos lato sensu (direitos difusos (inciso I), direitos coletivos (inciso II) e individuais homogêneos (inciso III)). Como características desses direitos, Rodolfo de Camargo Mancuso (2004, p. 88) cita a indeterminação dos sujeitos, a indivisibilidade do objeto, a intensa conflitualidade e a duração efêmera dos interesses difusos.

Os direitos coletivos também podem ser entendidos, em sentido estrito, como “interesses transindividuais indivisíveis de um grupo determinado ou determinável de pessoas 
reunidas por uma relação básica comum", nos termos do art. 21, Parágrafo Único, Inciso I, da Lei 12.016/2009, a qual dispõe sobre o mandado de segurança individual e coletivo.

É interessante notar que a lesão sofrida pelo grupo não é necessariamente acarretada por uma relação de fato, mas por relação jurídica básica viciada. Nas palavras de Mazzili (2012, p. 55):

Exemplifiquemos com uma cláusula ilegal em contrato de adesão. A ação civil pública que busque a nulidade dessa cláusula envolverá uma pretensão à tutela de interesse coletivo em sentido estrito pois o grupo atingido estará ligado por uma relação jurídica básica comum, que, nesse tipo de ação, deverá necessariamente ser resolvida de maneira uniforme para todo o grupo lesado

Em suma, os interesses coletivos são indivisíveis e de grupo, categoria ou classe de pessoas jurídicas determináveis ou determinadas. E o mais salutar é que a relação que as liga é jurídica básica.

A sentença obtida no âmbito desses direitos, conforme caso analisado, concede um bem indivisível entre os integrantes do grupo ofendido, uma vez que não quantificado, ou seja, não há que se dizer que o objeto obtido seja maior ou menor para uns ou outros, mas sim que há igualdade da pretensão entre todos.

Assim, se uma ação civil pública reconhece a ilegalidade de uma cláusula contratual, a pretensão obtida é indivisível e de interesse coletivo. Isto porque a ilegalidade é a mesma para todos os integrantes, não havendo como quantificar, para fins de indenização do grupo, a ilegalidade manifestada.

Também é se diz que essa acepção estrita de direitos coletivos traz em seu bojo a presença da individualidade e isso porque, ainda que o objeto da pretensão seja indivisível, há possibilidade de que cada um dos lesados busque a tutela individual em juízo.

Assim, uma cláusula abusiva inserida em contrato de adesão pode ser atacada por meio de ação civil pública (em proveito de todo o grupo lesado); entretanto, uma única pessoa também pode ajuizar ação individual para obter a nulidade dessa mesma cláusula (apenas em seu exclusivo benefício). Por outro lado, até mesmo os interesses difusos são transindividuais, pois, embora não permitam sua defesa estritamente individual em juízo, na verdade não passam de interesses individuais compartilhados por um grupo indeterminável de lesados. (MAZZILI, 2012, p. 61).

Desta forma, percebe-se a crescente eclosão de ações coletivas, como o caso das ações civis públicas, uma vez que a sua utilização, diante de ações individuais, se faz 
preferencial, por economia e celeridade processual, bem como em razão da segurança jurídica no trato de conflitos de natureza coletivos.

Interesses coletivos, bem como os difusos e individuais homogêneos, não são uma novidade. No entanto, nos últimos anos é que houve uma maior preocupação legislativa e doutrinária em identificá-los e lhes dar amparo jurisdicional através do processo coletivo. A corroborar com essa análise, Mazzili, com princípios processuais atinentes, faz a análise da importância crescente desses direitos e seus instrumentos de tutela:

Dessa forma, o legislador estipulou regras próprias sobre a matéria, especialmente para solucionar problemas atinentes à economia processual, à competência, à legitimação ativa, à destinação do produto da indenização e à imutabilidade da coisa julgada. (MAZZILI, 2012, p. 61).

Hodiernamente, portanto, não obstante a falta de uma codificação do processo coletivo, observa-se a ampliação do complexo normativo e jurisprudencial relacionado à tutela dos direitos difusos, coletivos e individuais homogêneos. Instrumentos processuais que buscam, de certa forma, retratar princípios de economia processual, celeridade, segurança jurídica, em função dos conflitos peculiares de uma sociedade cada vez mais de massa.

Cabe agora analisar a importância desses interesses sob um viés multicêntrico, uma vez que as ordens jurídicas precisam de mecanismos de interação em razão de fatores como o pluralismo cultural, a diversidade religiosa, bem como as diferenças de etnia, raças, gênero, e outros.

\section{0 transconstitucionalismo}

Como referencial teórico para análise da temática levantada, o presente estudo parte do transconstitucionalismo de Marcelo Neves (2009), que o instituiu com o objetivo de delinear as formas de relação entre ordens jurídicas diversas, ou seja, o desenvolvimento de formas de aprendizado recíproco e intercâmbio existente em cada caso concreto, principalmente em impasses atinentes a direitos coletivos, visto que tal questão se revela atual e pertinente dentro de uma perspectiva global cada vez mais calcada na conversação e entrelaçamento das normas estatais.

Diante da emergência de casos concretos transterritorializados relevantes para diversas ordens jurídicas envolvendo, inclusive, direitos coletivos, torna-se ideal a invocação 
do conceito de transcontitucionalismo. Tal importância vem do fato de que a cidadania, fundamento do Estado Democrático e Republicano (v. g., art. $1^{\circ}$, II, da Constituição Federal de 1988), deve ser tida como primeiro basilar para que seja factível o reconhecido supraprincípio da dignidade da pessoa humana, a qual, na visão de Siqueira Jr. e Oliveira (2007, p. 166), é fundamento constitucional da República Federativa do Brasil e deve ser o princípio norteador de todas as nações do planeta.

Dessarte, mostraremos a cidadania como forma de acesso aos direitos fundamentais e à dignidade da pessoa humana, tendo como coadjuvante de sua concretude a aplicação do método do transconstitucionalismo.

\subsection{Da gênese, conceito e relevância}

O transconstitucionalismo surgiu da questão levantada por Marcelo Neves (2009): o possível arquitetamento entre ordens jurídicas diversas que, apesar de serem subordinadas ao mesmo código binário de "lícito/ilícito"3 deste método, busca-se o aprendizado recíproco entre essas ordens.

Diferencia-se, segundo Marcelo Neves, do conceito de Constituições transversais trazido por Luhmann (1983), uma vez que estas se referem ao entrelaçamento entre o direito e a política, consistindo na correlação entre sistemas funcionais e acarretando na externalização e internalização de conteúdo entre categorias sociais que exercem funções diferentes e se reproduzem mediante códigos binários diferentes.

Frise-se então que, diversamente, o transconstitucionalismo se dá mediante ordens jurídicas diferenciadas, mas subordinadas ao mesmo código binário, e por meio de diversos programas e critérios. Essas ordens jurídicas são compostas de diversos atores de direito internacional, que são "todos aqueles que participam de alguma forma das relações jurídicas e políticas internacionais" (2012, p. 23).

\footnotetext{
${ }^{3} \mathrm{O}$ código binário, na visão de Niklas Luhmann, se caracteriza por ser a base que garante a própria autopoiese do sistema, uma vez que institui um valor positivo, ou seja, o que se entende como lícito, bem como um valor negativo, ou melhor, ilícito, permitindo, dentro do sistema jurídico, uma categorização de condutas como sendo compatíveis ou não com o direito, simplificando as questões que se encontram em seu entorno. (LUHMANN, 1983).
} 
Constata-se uma pluralidade em um mesmo sistema jurídico, possuindo cada ordem os seus próprios atos jurídicos, normas, procedimentos e dogmática jurídica. Essa diferenciação não é somente entre ordens jurídicas estatais com campos territoriais delimitados de validade, ou seja, conflito entre Estados que são conceituados como personalidade de direito internacional público que contém três elementos: "base territorial", "comunidade humana estabelecida nessa área" e "uma forma de governo não subordinada a qualquer autoridade exterior (REZEK, 2013, p. 199). Existe também uma diferenciação de "níveis" entre ordem jurídica estatal, internacional e supranacional, além de diferenças funcionais de ordens jurídicas transnacionais desligadas, por sua transterritorialidade, do direito estatal.

Buscam-se soluções fundadas no entrelaçamento entre as ordens jurídicas, sendo de fundamental importância o entendimento de que o transconstitucionalismo não caminha no sentido de levar a uma unidade constitucional do sistema jurídico mundial, mas sim da existência de um diálogo e uma conversação transconstitucional. Isso porque não seria cabível a aplicação universal de regramentos devido ao pluralismo jurídico mundial que vivenciamos e até mesmo se considerando a dificuldade que dos juristas para a definição de conceitos, os quais possuem compreensão "extraordinariamente frágil” (DWORKIN, 2002, p. 23).

A gênese do transconstitucionalismo está no conceito clássico de constitucionalismo, o qual se preocupa com a definição dos direitos e garantias fundamentais dentro de um determinado território. Luis Alberto David Araújo e Vidal Serrano afirmam:

Constitucionalismo é o movimento político, jurídico e social, pautado pelo objetivo de criar um pensamento hegemônico segundo o qual todo o Estado deve estar organizado com base em um documento fundante, chamado Constituição, cujo propósito essencial seria o de organizar o poder político, buscando garantir os direitos fundamentais e o caráter democrático de suas deliberações. (2011, p. 26)

É importante observar a dogmática da constituição para que, por intermédio de um sistema de orientações, possa se chegar a uma compreensão acerca desta. Nesse sentido, considera Canotilho (1994, p. 78):

No primeiro caso, procurar-se-á destilar um conceito ideal de constituição ou de tipos de constituição como produtos teoréticos; na segunda hipótese, 
importa sobretudo responder a questões concretas como que se defronta uma lei constitucional. Nomeadamente: que tarefas e funções devem ser confiadas à constituição de um país e sociedade concretos? Quais as matérias que têm dignidade constitucional? Deve a constituição limitar-se a uma ordem de competências? Ou deve conter um bloco de diretivas materiais correspondente às aspirações e interesses de uma sociedade num espaço e tempo historicamente situados? No caso afirmativo, de que forma? Através da imposição de tarefas e da definição de fins? Consagrando direitos subjetivos, econômicos, sociais e culturais, ou optando por simples cláusulas de socialidade e bem-estar?

Partindo da visão do constitucionalismo, retira-se um conceito pertinente de Constituição, embora também haja polêmica quanto a isso. Esse conceito proposto não é o existente, que se refere às visões amplas, tampouco às unilaterais. Não nos referimos à Constituição em seu conceito amplo, como tudo aquilo que remete à organização de alguma coisa designando a natureza peculiar de cada Estado. Também não uma visão unilateral, que trata a Constituição como um conjunto de elementos reais de poderes existentes numa sociedade. Nessa análise sobre a ampla possibilidade da conceituação de Constituição, observa Paulo Bonavides (2010, p. 80):

A palavra Constituição abrange toda uma gradação de significados, desde o mais amplo possível - a Constituição em sentido etimológico, ou seja, relativo ao modo de ser das coisas, sua essência e qualidades distintivas - até este outro em que a expressão se delimita pelo adjetivo que a qualifica, a saber, a Constituição política, isto é, a Constituição do Estado, objeto aqui de exame.

Noutras palavras, Maria Garcia analisa não só o conceito, mas também primordial característica acerca das Constituições, afirmando serem resultantes de um determinado período da história, havendo a transformação deste em um instrumento jurídico-político para a organização da sociedade política marcados, portanto, pela circunstancialidade resumida em "legitimidade, eficácia, pressões, impasses, forças, poderes, conveniências e ideais" (2004, p. 214).

A Constituição deve ser vista na ideologia do constitucionalismo. Assim, é um documento com a função de instrumento tendente assegurador das liberdades e proclamador dos direitos fundamentais através da instituição da separação de poderes. Luís Roberto Barroso (2011, p. 97), em corroboração, afirma ser possível conceituar a Constituição como sendo: 
a) do ponto de vista político, como o conjunto de decisões do poder constituinte ao criar ou reconstruir o Estado, instituindo os órgãos de poder e disciplinando as relações que manterão entre si e com a sociedade;

b) do ponto de vista jurídico, é preciso distinguir duas dimensões:

(i) em sentido material, i.e., quanto ao conteúdo de suas normas, a Constituição organiza o exercício do poder político, define os direitos fundamentais, consagra valores e indica fins públicos a serem realizados;

(ii) em sentido formal, i.e, quanto à posição no sistema, a Constituição é a norma fundamental e superior, que regula o modo de produção das demais normas do ordenamento jurídico e limita o seu conteúdo.

A Constituição cria ou reconstrói o Estado, disciplinando sobre os direitos fundamentais, valores e fins públicos, bem como o modo de produção e conteúdo das futuras normas que passarão a fazer parte da ordem jurídica através da organização e imposição de limites ao Poder Público.

Nesse ínterim, importa analisar os direitos fundamentais pois são tão basilares das Constituições que até mesmo Appio considera que “[...] a proteção judicial dos direitos fundamentais e a tutela jurisdicional das minorias se constituem na base da democracia constitucional.” (2008, p. 382). Apesar da polêmica em torno da cognição de direitos fundamentais e, muito embora existam direitos só formalmente incluídos como fundamentais, os direitos fundamentais podem ser considerados como a consolidação das pretensões da dignidade da pessoa humana.

Para Gilmar Mendes "Os direitos e garantias fundamentais, em sentido material, são, pois, pretensões que, em cada momento histórico, se descobrem a partir da perspectiva do valor da dignidade da pessoa humana" (2011, p. 159). José Afonso da Silva acredita que eles devem servir em garantia de digna convivência, na qual impera igualdade e liberdade entre todos. Para este último, fundamental seria as situações necessárias da pessoa humana, ou melhor, indispensáveis para a sua sobrevivência (1992, p. 163-164). Alexy, por sua vez, defende a sua compreensão através de teorias variadas, tanto históricas que explicam seu desenvolvimento, como filosóficas que visam seus fundamentos, e sociológicas que falam das funções dos direitos fundamentais, entre outras (2012, p. 32).

Sarlet (2012) traz a distinção entre as expressões "direitos fundamentais" e "direitos humanos", que são comumente utilizadas como sinônimos. O primeiro termo se refere aos direitos da pessoa humana, que são reconhecidos e positivados no âmbito do direito constitucional positivo de determinado Estado. Já da segunda expressão é possível auferir que são correlatas com os documentos de direito internacional, uma vez que reconhece o ser 
humano apartado de determinada ordem jurídica constitucional ensejando validez universal e um consequente caráter supranacional. Este último não pode ser considerado sinônimo de "direitos naturais", sendo divergente do ponto de vista, até mesmo dos jusnaturalistas. Isso porque a própria normatização em dispositivos de direito internacional se desvincula da ideia de direito natural, posto que é pacífica a noção de que as liberdades públicas não se confundem com as noções naturais do homem, assim como expõe Norberto Bobbio (1992, p. 26).

Apesar do vasto rol de denominações existentes quanto a esses direitos, Maria Garcia afirma:

Já referimos, anteriormente, uma característica desses direitos, que é a sua diversidade semântica. As variadas denominações encontradas para sua designação não deve, contudo, constituir empecilho à localização de um núcleo centralizador que distingue esses direitos, além das duas características básicas apontadas: os direitos fundamentais são direitos públicos subjetivos não somente do cidadão, em sentido estrito, senão que determinam um status jurídico ou a liberdade à pessoa; ao mesmo tempo em que são elementos essenciais do ordenamento jurídico de uma sociedade. (2004, p. 208-209)

O constitucionalismo se originou dos movimentos político-sociais que intentavam restringir o poder autoritário do Estado. Exigiam-se regras positivadas em uma Constituição, as quais favorecessem a preponderância dos direitos fundamentais mediante o afastamento da visão autoritária que prevalecia no antigo regime.

Nas palavras de Canotilho (1994, p. 51), o constitucionalismo consiste em uma:

[...] teoria (ou ideologia) que ergue o princípio do governo limitado indispensável à garantia dos direitos em dimensão estruturante da organização político-social de uma comunidade. Neste sentido, o constitucionalismo moderno representará uma técnica específica de limitação do poder com fins garantísticos. O conceito de constitucionalismo transporta, assim, um claro juízo de valor. É, no fundo, uma teoria normativa da política, tal como a teoria da democracia ou a teoria do liberalismo.

Ressalte-se que na visão do referido autor há vários constitucionalismos, como o americano, o inglês, o francês. Canotilho prefere a expressão "movimentos constitucionais" ao se referir a elas.

Divide-se história do constitucionalismo em diversos grandes grupos ou eras, a saber: Idade Antiga, Idade Média, Idade Moderna e Idade Contemporânea. 
Dentro desse desenvolvimento histórico, espera-se que, no futuro, se alcance a consolidação dos direitos fundamentais de terceira dimensão (direitos coletivos), como já se tem tentado. Para isso, deve-se partir do fortalecimento da existência de uma constituição social garantidora dos direitos relacionados à fraternidade e à solidariedade.

Com a adoção de certas medidas, almeja-se estabelecimento de um consenso entre o constitucionalismo moderno e algumas caraterísticas do contemporâneo, tidas como excedentes, e a contemplação de alguns valores.

As Constituições futuras deverão se atentar aos valores: da verdade, não prometendo o que não poderá cumprir; da solidariedade, mantendo esta como essência numa nova perspectiva de igualdade como propulsor da justiça social e dignidade da pessoa; do consenso, sendo fruto de acordo democrático; da continuidade, não desconsiderando os avanços já alcançados; da participação, fortalecendo a ideia de Estado de Direito Democrático; de integração, que nas palavras de Pedro Lenza (2012, p. 60) se refere a "previsão de órgãos supranacionais para a implementação de uma integração espiritual, moral, ética e institucional entre os povos"; e de universalização, com o estabelecimento de direitos fundamentais em todas as Constituições internacionais futuras. (Lenza, 2012).

Entretanto, com o transcorrer do tempo, houve a crescente inclusão de relações transterritoriais com implicações normativas fundamentais, gerando a necessidade de abertura do constitucionalismo para além do Estado, acarretando o surgimento de uma nova visão, a do transconstitucionalismo.

Observando o transconstitucionalismo a partir do constitucionalismo, o transconstitucionalismo é um constitucionalismo que intenta solucionar problemas jurídicoconstitucionais que se apresentam simultaneamente em ordens heterogêneas.

A relação transconstitucional entre ordens jurídicas resulta das prestações recíprocas que podem haver através de interpretações e interferências entre elas e, principalmente, do fato de que essa diversidade de ordens jurídicas pertencem ao mesmo sistema funcional da sociedade global. Trata-se do direito consistente num sistema que se apresenta com base em um mesmo código binário, distinguindo-se lícito de ilícito.

A "conversação" entre ordens jurídicas diversas deve acarretar numa cooperação ininterrupta entre elas, uma vez que os conflitos entre ordens ocorrem de maneira contumaz. Ademais, deve-se buscar uma solução para essas disputas sem que haja imposição de uma ordem jurídica em relação à outra. Pondera Marcelo Neves (2009, p. 118-119): 
No caso do transconstitucionalismo, as ordens se inter-relacionam no plano reflexivo de suas estruturas normativas que são autovinculantes e dispõem da primazia. Trata-se de uma "conversação constitucional", que é incompatível com um "constitucional diktat" de uma ordem em relação a outra. Ou seja, não cabe falar de uma estrutura hierárquica entre ordens: a incorporação recíproca de conteúdos implica uma releitura de sentido à luz da ordem receptora. [...] O transconstitucionalismo faz emergir, por um lado, uma "fertilização constitucional cruzada". As cortes constitucionais "citam-se reciprocamente não como precedente, mas como autoridade persuasiva.

O transconstitucionalismo objetiva delinear as maneiras de relação entre ordens jurídicas diversas. Tais ordens, presentes num mesmo sistema e subordinadas ao mesmo código binário de lícito/ilícito possuem seus próprios atos, normas, procedimentos e dogmática jurídicos. Essa divergência entre normas se dá em "níveis": estatal, supranacional, internacional e transnacional.

As ordens não podem ser consideradas isoladas, necessitando entre elas um entrelaçamento, assim como reza o transconstitucionalismo. Para tanto, existem diversas “pontes de transição" entre as ordens jurídicas. O entrelaçamento poderá ser considerado efetivo, por exemplo, quando houver a introdução de um tratado internacional no direito interno, ou mesmo quando as regras de direito internacional privado procuram ligar consensualmente a relação das ordens jurídicas estatais.

Sobre tratado internacional, Guido Fernando Silva Soares explica de forma sucinta:

Os tratados internacionais são atos solenes entre os Estados, tão antigos quanto as relações amistosas ou litigiosas entre grupos políticos autônomos [...] A necessidade de petrificação dos direitos e deveres internacionais, em documentos claros e permanentes no tempo, fez com que, tradicionalmente, os tratados e convenções internacionais se denominassem jus scriptum, em atenção aos valores expressos pelos conceitos palavras escritos, desde os primórdios da civilização humana. (SOARES, 2004, p. 58)

Embora tratados internacionais sejam considerados no transconstitucionalismo como maneira de entrelaçamento entre as ordens e, tomando como referência os voltados à pessoa humana (e, portanto, à promoção da sua dignidade) trazemos a lume a opinião de Celso Albuquerque de Mello, que defende a consequência de subjetividade internacional do indivíduo, pois "o transformam portador de direitos e deveres perante a ordem internacional" (2002, p. 907). 
Nesse entrelaçamento exigido pelo transconstitucionalismo, os juízes e tribunais são fundamentais. Isso porque Marcelo Neves (2009. p. 58) considera que, dentro de uma determinada relação jurídica, eles atuam como sendo o ponto central das ordens jurídicas envolvidas levando-se em consideração a ótica de cada uma delas. Assim, tendo em vista a existência de uma sociedade mundial e sistemas jurídicos multicêntricos, há, no âmbito de cada ordem jurídica envolvida, a ótica de juízes e tribunais como representação do centro delas. Estes centros, por sua vez, acabam por enxergar as outras ordens jurídicas externas, que também possuem seu próprio centro do ponto de vista interno, como possuidoras de "periferias" formadas pelos seus respectivos juízes e tribunais, uma vez que estão sendo analisadas de um ponto de vista externo. São essas periferias, compostas por juízes e tribunais alheios à ordem jurídica tomada como referência e portanto possuidora de seu próprio centro, que são consideradas para poder proporcionar a internalização de aprendizagem que propõe o transconstitucionalismo.

Nesse sentido, por exemplo, para o judiciário brasileiro, tanto os juízes de outros Estados quanto os tribunais de ordens jurídicas internacionais, supranacionais e transnacionais, quando suas decisões são por ele levadas em conta, apresentam-se como periferia e vice-versa. (NEVES, 2004, p. 58)

A importância dos juízes e tribunais se destaca principalmente no concernente às relações de observação mútua, das quais se desenvolvem formas de intercâmbio e aprendizagem. Como o aprendizado é em cada caso concreto, não haverá a construção de um primado definitivo de uma das ordens ou, em outras palavras, uma ultima ratio jurídica.

Por outro lado, ainda que o entrelaçamento através de Tribunais seja o mais relevante, nem todos ocorrerão por eles. Há, numerosas vezes, a incorporação de normas provenientes de outra ordem, sem que haja tribunais como mediadores desse diálogo. Ou até uma reinterpretação da própria ordem quando da agregação de outros sentidos normativos provenientes diretamente de outros ordenamentos. Igualmente, o aprendizado recíproco em outros níveis do sistema jurídico, como na relação informal entre legislativo, governos e administrações de diversos países.

Consideramos que isso ocorre porque as incorporações decorrentes das várias interpretações não podem advir somente dos juízes e procedimentos formais, estruturando uma sociedade fechada, mas também da "incorporação das ciências sociais e também nas 
teorias jurídico-funcionais, bem como nos métodos de interpretação voltados para atendimento do interesse público e do bem-estar geral", afirmativa de Haberle (1991, p. 12) dentro de sua análise de exigência de uma interpretação constitucional voltada para a realidade (1991, p. 12).

A vivência de problemas comuns a mais de uma ordem jurídica ensejadores de modelos normativos diversos não é recente. $\mathrm{Na}$ verdade, são apreciados desde a experiência do direito internacional clássico ${ }^{4}$.

É dessa emergência de casos jurídicos transterritorializados que surge o transconstitucionalismo. Cada ordem jurídica invoca os seus modelos com seus próprios programas e critérios para solucionar casos concretos. Por conseguinte, presenciamos colisões, surgindo a necessidade de pontes de transição para o entrelaçamento entre elas.

Esse processo de aprendizado recíproco está notadamente revestido de dinamicidade. Isso porque a solução para cada caso concreto deverá estar de acordo com a sociedade, não podendo haver o bloqueio ou destruição da norma concorrente ou cooperadora, mas sim a motivação intercâmbio em futuros "encontros" para o enfrentamento de casos comuns.

Qual seria o remédio para choques que venham ocorrer entre ordens jurídicas? Como afirmado, o método do transconstitucionalismo deve consistir numa conversação entre as ordens jurídicas, não podendo se resumir ao modelo de identidade de apenas um ordenamento determinado.

O problema, entretanto, surge especialmente quando um dos polos da relação de observação recíproca não aceita tolerar a liberdade do outro, impedindo interações e levando a um bloqueio recíproco. Nas ordens confrontadas com problemas comuns, principalmente quando essas adversidades têm natureza jurídico-constitucional, privilegia-se a alteridade, a qual significa "busca constante de rearticular a identidade em face de outro" (NEVES, 2009, p. 276).

Almeja-se a composição de um método transconstitucional que vise à contínua reconstrução de uma identidade constitucional que sopese a alteridade. Não se trata de apenas

\footnotetext{
4 Apesar de serem ambos consistentes em períodos históricos do moderno Direito Internacional, o direito internacional clássico antecede e diverge do direito internacional contemporâneo. No primeiro, tem-se como predominante as relações entre os Estados, se constituindo estes como únicos sujeitos de Direito Internacional, presenciando-se um intermédio existente através de tratados de comércio, aliança, navegação e paz, além dos costumes. Diferentemente do segundo, o qual adere aos sujeitos as organizações internacionais, que criam normas para os Estados e indivíduos, fazendo prosperar a existência de tratados multilaterais.
} 
sucumbir a uma determinada identidade de modo a negar a própria, mas sim de abertura para que outras ordens também sejam levadas em conta nos casos concretos.

\begin{abstract}
Nesse sentido, é fundamental, no plano da construção de uma metodologia do transconstitucionalismo, que se considere ser indispensável à reconstrução permanente da "identidade constitucional" por força de uma consideração permanente da alteridade. Isso não significa a negação da identidade conforme um modelo inocente de pura convergência, e sim a prontidão para uma abertura não apenas cognitiva, mas também normativa para outra(s) ordem(ns) entrelaçada(s) em casos concretos. Evidentemente, permanece uma incerteza de resultados, mas só mediante essa disposição é possível absorver o dissenso originário. O caminho contrário leva ao bloqueio recíproco na solução de relevantes problemas constitucionais, tanto no plano dos direitos humanos e fundamentais quanto no âmbito da organização (controle e limitação) do poder. (NEVES, 2009, p. 274-275).
\end{abstract}

O transconstitucionalismo deve ser utilizado como ponto de partida para a solução de emblemas que envolve direitos fundamentais e humanos à medida que viabiliza a articulação de regras e princípios em face do caso concreto. Segundo Marcelo Neves (2009, p. 275), isso possibilita que o "desenvolvimento de um método do transconstitucionalismo abre a possibilidade de construção de uma racionalidade transversal na relação entre princípios e regras de ordens jurídicas diversas."

O modelo de alteridade encontra retenção no sistema jurídico mundial de níveis múltiplos. Marcelo Neves (2009) explica que, diante de ordens jurídicas não propensas à conversação transconstitucional, não se deve apenas impor uma identidade, mas sim buscar na ordem dos outros componentes que possam proporcionar a sua autotransformação, ocasionando um primeiro passo para o diálogo transconstitucional.

Além do fato de não ser conveniente a adoção de uma hierarquia, ou seja, a nãoimposição de uma determinada identidade constitucional para outras ordens jurídicas, também não se deve restringir o transconstitucionalismo a uma simples condição de fragmentação desorganizada, diferenciando as ordens jurídicas e analisando suas fundamentações de maneira construtiva.

Portanto, com base em uma metodologia do transconstitucionalismo cabe rejeitar tanto um modelo metódico hierárquico quanto a simples constatação da fragmentação do direito, sem horizonte metodológico. Em face da fragmentação, o método transconstitucional precisa desenvolver-se na busca de construir "pontes de transição" que possibilitem um relacionamento mais construtivo (ou menos destrutivo) entre ordens jurídicas, mediante a 
articulação pluridimensional de seus princípios e regras em face de problemas jurídico-constitucionais comuns, dependentes de soluções suportáveis para todas as ordens envolvidas, sem uma última instância decisória. Antes de autoridade, o transconstitucionalismo precisa de método. (NEVES, 2009, p. 276-277)

Sob esse prisma, algumas soluções transconstitucionais, nas quais se incluem conflitos envolvendo direitos coletivos, podem ser propostas. Tema a seguir analisado.

\section{Aplicabilidade do método aos direitos coletivos na sociedade multicêntrica}

O conceito de pluralismo e sociedade multicêntrica está dentro da pluralidade de sistemas envolvendo a convivência de esferas divergentes caracterizadas pela heterogeneidade social, cultural, ideológica, religiosa e étnica. Tendo como parâmetro o âmbito mundial, sociedade multicêntrica é presenciada na ausência de um núcleo duro conceitual, proporcionada pelas mudanças modernas trazidas especialmente pela globalização.

O incremento da complexidade social levou ao impasse da formação social diferenciada hierarquicamente da pré-modernidade, fazendo emergir a pretensão crescente de autonomia das esferas de comunicação, em termos de sistemas diferenciados funcionalmente na sociedade moderna. Há não só um desintricamento de lei, poder e saber, nem apenas a obtenção da liberdade religiosa e econômica pelo homem, mas um amplo processo de diferenciação sistêmico-funcional.

Mediante esse processo, a sociedade torna-se 'multicêntrica' ou 'policontextual'. Isso significa, em primeiro lugar, que a diferença entre sistema e ambiente, desenvolve-se em diversos âmbitos de comunicação, de tal maneira que se afirmam distintas pretensões contrapostas de autonomia sistêmica. E, em segundo lugar, na medida em que toda diferença se torna 'centro do mundo', a policontexturalidade implica uma pluralidade de autodescrições da sociedade, levando à formação de diversas racionalidades parciais conflitantes. Falta, então, uma diferença última, suprema, que possa impor-se contra todas as outras diferenças. Ou seja, não há um centro da sociedade que possa ter uma posição privilegiada para sua observação e descrição; não há um sistema ou mecanismo social a partir do qual todos os outros possam ser compreendidos (NEVES, 2009, p. 23-24).

É dentro desse contexto que surge a visão do transconstitucionalismo de Marcelo Neves, propondo o diálogo e intercâmbio entre esse pluralismo. A título de exemplo do transconstitucionalismo como método de solução de conflitos envolvendo direitos coletivos, há casos que envolvem ordens jurídicas estatais e extra-estatais de comunidades nativas. 
São comuns conflitos de direitos fundamentais entre os costumes indígenas e a ordem estatal. É o que ocorre quando se trata de liberdade sexual, já que a manutenção de relações sexuais com menores de 14 anos é considerada normal e juridicamente lícita nos costumes indígenas, enquanto a ordem estatal brasileira considera como sendo crime de estupro de vulnerável, nos termos do art. 218 do Código Penal (com nova redação dada pela Lei 12.015/2009).

Há também o direito consuetudinário de algumas comunidades indígenas que praticam homicídios de recém-nascidos quando estes apresentam alguma deficiência física ou mental, ou das que tiram a vida de um dos gêmeos recém-nascidos. Entre essas comunidades indígenas, a vida só tem sentido se não marcada por excessivo sofrimento para o indivíduo e a comunidade, sendo tranquila e amena. Em contrapartida, iniciativas legislativas no Brasil ( $v$. g., Projeto de lei n. 1.057 de 2007) visam criminalizar essas condutas. Mas o significado atribuído à vida e à morte pelos indígenas não parece ser menos digno do que o sentido que lhes atribui o cristianismo. Trata-se de conflito em que de um lado está o direito à vida de um sujeito individual e, de outro, o direito à vida do sujeito coletivo.

Marcelo Neves (2009), nos casos acima mencionados, apresenta soluções. Nas práticas sexuais envolvendo menores de 14 anos das comunidades indígenas, considerando que isso exige uma postura judicial de cuidadosa prudência entre ordens normativas diversas, depende da análise concreta dos direitos fundamentais envolvidos.

No costume do homicídio praticado em recém-nascidos com deficiência, Marcelo Neves (2009) parece ser a favor da manutenção desse tipo de cultura dos indígenas, adotando uma solução transconstitucional apenas para tornar o Estado um supervisor com o fim de garantir que a deliberação dos indígenas ocorra de forma livre, sem abuso nos processos internos.

São conflitos que abarcam direitos coletivos de um grupo (indígenas) e a ordem jurídica estatal brasileira. Percebe-se a relevância da aplicação do método do transconstitucionalismo envolvendo essa categoria de direitos coletivos em conflito, tanto em sentido amplo (povo como elemento integrante do Estado), quanto em sentido estrito (comunidade indígena).

Na sociedade internacional, o transconstitucionalismo, como método de resolução de conflitos, é utilizado na busca de interação e conversação de ordens jurídicas. Exemplo: o próprio processo de universalização dos direitos humanos (por meio de uma ordem jurídica 
supranacional balizada na dignidade da pessoa humana) frente aos sistemas normativos estatais que decorrem do pluralismo cultural e religioso presentes em países que permitem, por exemplo, a mutilação da genital feminina (África e Oriente Médio), ou a aplicação da pena de morte (Estados Unidos e a Indonésia). Há ainda situações mais desafiadoras, como o recém denominado Estado Islâmico que aterroriza, nos dias atuais, a sociedade internacional (e por conseguinte, a dificuldade da concreção de direitos, em especial, os coletivos), pela sua interpretação radical, e equivocada, do islamismo.

Acredita-se, dessa forma, ser possível alcançar um aprendizado difuso entre os sistemas conflitantes, de maneira a proporcionar, inclusive, uma reinterpretação e ascensão de considerações a respeito dos direitos coletivos, visto que esses últimos apresentam, tal como explicitado, uma importância cada vez maior nos dias atuais. Portanto, atinge-se a alteridade e aprendizagem, corroborando com o desenvolvimento e crescimento da sociedade pela maior consideração dos direitos coletivos.

\section{Considerações Finais}

O transconstitucionalismo, ao ser proposto como método apaziguador de conflitos, pode obter resultados significativos. Neste sentido, analisou-se divergências entre ordens jurídicas submetidas ao mesmo código binário de lícito/ilícito, porém possuidoras de diversos programas e critérios.

Foi proposta uma simbiose harmônica entre as normas de ordenamentos jurídicos envolvidos. No entanto, deve-se manter a cautela para a não existência de uma única unidade constitucional, de modo que o transconstitucionalismo acarretaria apenas na imposição de uma acepção jurídica sobre a outra.

O transconstitucionalismo deve ser entendido sob um viés contemporâneo, não obstante à sua origem do constitucionalismo clássico. Ele partiu da necessidade de ampliação de relações transterritoriais, de modo a levar em consideração a definição dos direitos e garantias fundamentais coletivos não somente em um determinado território, mas também além dele.

Assim, partindo da ideologia de que atualmente, na perspectiva de desavenças transterritoriais, o tendão de Aquiles consiste nas controvérsias atinentes a direitos coletivos, 
o método do transconstitucionalismo apresenta-se como importante meio de realce desses direitos.

O transconstitucionalismo utilizado para este fim, no entanto, tem resultados exíguos no caso de sua aplicação em ordens jurídicas desconhecedoras dos direitos fundamentais, bem como nas que não aceitam a liberdade da outra ordem ao ponto de impedir interações.

Deve-se, portanto, caminhar no sentido de conversação entre as ordens jurídicas, priorizando os direitos fundamentais sem que haja entre elas uma hierarquia (baseada na autoridade). Essa é a proposta do transconstitucionalismo como método propulsor da concreção dos direitos coletivos na sociedade multicêntrica.

\section{Referências}

ALEXY, Robert. Teoria dos direitos fundamentais. Trad. Virgílio Afonso da Silva. São Paulo: Malheiros, 2012.

APPIO, Eduardo Fernando. Direito das minorias. São Paulo: RT, 2008.

ARAUJO, Luis Alberto David; JÚNIOR, Vidal Serrano Nunes. Curso de direito constitucional. São Paulo: Editora Verbatim, 2011.

BARROSO, Luís Roberto. Curso de direito constitucional contemporâneo: os conceitos fundamentais e a construção do novo modelo. 3. ed. São Paulo: Saraiva, 2011.

- Interpretação e aplicação da constituição: fundamentos de uma dogmática constitucional transformadora. 7. ed. rev. São Paulo: Saraiva, 2009.

BOBBIO, Norberto. A era dos direitos. Trad. Carlos Nelson Coutinho. Rio de Janeiro: Elsevier, 1992.

. O futuro da democracia: uma defesa das regras do jogo. 6. ed. Paz e Terra, 1986.

BONAVIDES, Paulo. Constituinte e Constituição: a democracia, o federalismo, a crise contemporânea. 3. ed. São Paulo: Malheiros, 2010.

- Teoria constitucional da democracia participativa: por um direito constitucional de luta e resistência, por uma nova hermenêutica, por uma repolitização de legitimidade. 3. ed. São Paulo: Malheiros, 2008.

. Curso de direito constitucional. 25. ed. São Paulo: Editora Malheiros, 2010.

CANOTILHO, José Joaquim Gomes. Constituição dirigente e vinculação do legislador: contributo para a compreensão das normas constitucionais programáticas. Coimbra: Coimbra, 1994. 
Estudo sobre direitos fundamentais. 2. ed. Coimbra: Almedina, 2008.

DANTAS, Miguel Calmon. Constitucionalismo dirigente e pós-modernidade. 1. ed. São Paulo: RT, 2009.

DWORKIN, Ronald. Levando os Direitos a sério. Trad. Nelson Boeira. São Paulo: Martins Fontes, 2002.

GARCIA, Maria. Desobediência civil. 2.ed. São Paulo, RT, 2004.

HABERLE, Peter. Hermenêutica com constitucional: a sociedade aberta dos intérpretes da Constituição - contribuição para a interpretação pluralista e "procedimental" da Constituição. Trad. Gilmar Mendes, Porto Alegre: Sergio Antonio Fabris Editor, 1991.

LEITE, George Salomão; Sarlet, Ingo Wolfgang (Coord). Direito fundamentais e estado constitucional: estudos em homenagem a J. J. Gomes Canotilho.

MANCUSO, Rodolfo de Camargo. Interesses difusos: conceito e legitimação para agir. São Paulo: Editora Revista dos Tribunais. 6 ${ }^{\text {a }}$ ed., 2004.

MAZZILLI, Hugo Nigro. A defesa dos interesses difusos em juízo: meio ambiente, consumidor, patrimônio cultural, patrimônio público e outros interesses. 24. Ed. São Paulo: Saraiva, 2012.

MELLO, Celso D. de Albuquerque. Curso de direito internacional público. 11. ed. rev. e aum. Rio de Janeiro: Renovar, 2002.

MENDES, Gilmar Ferreira. Curso de direito constitucional. 6. ed. rev. e atual. São Paulo: Saraiva, 2011.

NEVES, Marcelo. Transconstitucionalismo. São Paulo: WMF Martins Fontes, 2009.

OLIVEIRA, Miguel Augusto Machado; SIQUEIRA Jr., Paulo Hamilton. Direitos Humanos e Cidadania. São Paulo: RT, 2007.

REZEK, José Francisco. Direito internacional público: curso elementar. 14. ed. rev, aumen. e atual. São Paulo: Saraiva, 2013.

SARLET, Ingo Wolfgang. A eficácia dos direitos fundamentais: uma teoria geral dos direitos fundamentais na perspectiva constitucional. 11. ed. rev. e atual. Porto Alegre: Livraria do Advogado, 2012.

SCHIMITT, Carl. Teoría de la Constituición. Trad. Francisco Ayala. Madrid: Alianza Editorial, 1996.

SILVA, José Afonso da. Comentário contextual à Constituição. 3. ed. São Paulo: Malheiros, 2007. 
SILVA, José Afonso da. Curso de direito constitucional positivo. 34. ed. rev. e atual. São Paulo: Malheiros, 1992.

SOARES, Guido Fernando Silva. Curso de direito internacional público. 2. ed. São Paulo: Atlas, 2004.

VARELLA, Marcelo D. Direito internacional público. 4. ed. São Paulo: Saraiva, 2012. 